\title{
INFLUENCE OF EXOGENOUS LACTOFERRIN ON THE OXIDANT/ ANTIOXIDANT BALANCE AND MOLECULAR PROFILE OF HORMONE RECEPTOR-POSITIVE AND -NEGATIVE HUMAN BREAST CANCER CELLS IN VITRO
}

\author{
I.V. Zalutski', N.Y. Lukianova' ${ }^{2}$ D.M. Storchai ${ }^{2}$, A.P. Burlaka', Y.V. Shvets ${ }^{2}$, T.V. Borikun' ${ }^{2}$ I.M. Todor', \\ V.S. Lukashevich', Y.A. Rudnichenko ${ }^{2}$, V.F. Chekhun ${ }^{2}$ * \\ ${ }^{1}$ State Scientific Institution “Institute of Physiology”, NAS of Belarus, Minsk 220072, Republic of Belarus \\ ${ }^{2}$ R.E. Kavetsky Institute of Experimental Pathology, Oncology and Radiobiology, NAS of Ukraine, \\ Kyiv 03022, Ukraine
}

\begin{abstract}
Aim: To investigate the mechanisms of cytotoxic activity and pro-/antioxidant effect of lactoferrin on hormone receptor-positive and receptor-negative breast cancer cells in vitro. Materials and Methods: The study was performed on receptor-positive (MCF-7, T47D) and receptor-negative (MDA-MB-231, MDA-MB-468) human breast cancer cell lines. Immunocytochemical staining, flow cytometry, low-temperature electron paramagnetic resonance, and the Comet assay were used. Results: Upon treatment with lactoferrin, the increased levels of reactive oxygen species $(\mathrm{ROS})(p<0.05)$, NO generation rate by inducible NO-synthase $(p<0.05)$ and the level of "free" iron $(p<0.05)$ were observed. Moreover, the effects of lactoferrin were more pronounced in receptor-negative MDA-MB-231 and MDA-MB-468 cells. These changes resulted in increased expression of proapoptotic Bax protein $(p<0.05)$, reduced expression of the antiapoptotic Bcl-2 protein $(p<0.05)$ and level of not-oxidized mitochondrial cardiolipin (1.4-1.7-fold, $p<0.05)$. This, in turn, caused an increase in the percentage of apoptotic cells (by 14-24\%,p<0.05). Cytotoxic effects of lactoferrin were accompanied by an increase in the percentage of DNA in the comet tail and blocking cell cycle at $\mathrm{G}_{2} / \mathrm{M}$ phase, especially in receptor-negative cell lines. Conclusion: The study showed that exogenous lactoferrin causes a violation of an antioxidant balance by increasing the level of ROS, "free" iron and NO generation rate, resalting in the blocking of cell cycle at $\mathbf{G}_{2}$ /M-phase and apoptosis of malignant cells.
\end{abstract}

Key Words: lactoferrin, breast cancer, oxidative status, antioxidant status, apoptosis.

Breast cancer $(\mathrm{BC})$ is a heterogeneous disease that varies by the morphological and molecular structure as well as by the clinical course, and therefore requires different approaches to diagnosis and treatment. To date, the expansion of knowledge about the role of metalloproteins in malignant transformation and tumor progression as important components of metabolism is a great interest. In this respect exploration of iron metabolism disorders in cancer patients become increasingly relevant in recent years [1-3]. The role of such violations in the tumorigenesis is already proven by clinical and experimental studies. There is evidence that the concentration of iron and iron-regulating proteins correlates with tumor aggressiveness of BC [4]. Among the least studied ironcontaining proteins is lactoferrin (LF) - a protein with a unique set of biological properties of different nature. An important feature of LF is its ability to bind to nucleic acids and to regulate cell cycle, cell proliferative activity, and affect the oxidant/antioxidant balance in the cells. The synthesis and secretion of LF may be constitutional (e.g., secretory glands) or controlled by sex hormones [5].

Nowadays the search and development of means of drug therapy with antioxidant properties is per-

Submitted: May 15, 2017.

${ }^{\star}$ Correspondence: E-mail: chekhun@onconet.kiev.ua Abbreviations used: BC - breast cancer; EPR - electron paramagnetic resonance; LF - lactoferrin; ROS - reactive oxygen species; SOD - superoxide dismutase. formed worldwide. Experimental studies have shown that natural antioxidant proteins (ceruloplasmin, superoxide dismutase (SOD), and alkaline phosphatase) have the highest activity compared with synthetic analogs. However, in modern oncology practice, only ceruloplasmin-based drugs are used.

The lack of studies aimed at assessing the impact of LF on the growth of malignant tumors, because of its ability under certain conditions to exercise prooxidative properties is one of the reasons why LF is not applied in practice. The existence of functionally different phenotypic and molecular genetic characteristics of $\mathrm{BC}$ cells with different biological aggressiveness is the basis for the development of methods for selective therapeutic intervention, which should be based on the results of experimental LF studies. Thus, our aim was to investigate the mechanisms of cytotoxic activity and pro/antioxidant effect of LF on hormone receptor-positive and -negative $B C$ cells.

\section{MATERIALS AND METHODS}

Cellculture. Hormone-positive MCF-7andT47Dand hormone-negative MDA-MB-231 andMDA-MB-468 cell lines were used in our study. Cells were provided by the Bank of Cell Lines of Human and Animal Tissues at R.E. Kavetsky Institute of Experimental Pathology, Oncology, and Radiobiology of NAS of Ukraine. All cells were cultured in DMEM (Sigma, USA), supplemented with recombinant human insulin (Life Technologies, USA; $0.01 \mathrm{mg} / \mathrm{ml}$ ) and 10\% fetal bovine serum (Sigma 
Aldrich, USA). All cultures were incubated in humidified atmosphere with $5 \% \mathrm{CO}_{2}$ at $37^{\circ} \mathrm{C}$.

Measurement of cell viability, using the MTT assay was performed as described previously [6]. The cytotoxic effect of exogenous LF, wich was synthesized at the State Scientific Institution "Institute of Physiology" (Minsk, Republic of Belarus) was measured in the dose range of $2-300 \mu \mathrm{g} / \mathrm{ml}$.

Immunocytochemical study of the expression of apoptosis regulators in BC cells was performed using monoclonal mouse anti-human Bcl-2 (clone 124) and polyclonal rabbit anti-human Bax antibodies (DakoCytomation, Denmark). For the detection reaction visualization, UltraVision Quanto Detection System HRP DAB (Thermo Fisher Scientific, USA) was used.

Cells for immunocytochemical studies were grown on glass cover slips, fixed in the cooled mixture of methanol:acetone $(1: 1)$ at $-20^{\circ} \mathrm{C}$ for $120 \mathrm{~min}$, washed in PBS and incubated with 1\% BSA for $20 \mathrm{~min}$. Primary monoclonal antibodies were diluted in the blocking buffer and kept at a room temperature for one hour, followed by incubation with UltraVision Quanto Detection System for 10 and $15 \mathrm{~min}$; after the washing, the immune reaction was visualized by using DAB Quanto. When immunocytochemical reactions were completed, the cells were stained by Mayer's hematoxylin for $10-15 \mathrm{~s}$ and placed in Faramount Aqueous Mounting Medium (DakoCytomation, Denmark). Evaluation of the results was carried out in 3 visual fields by light microscopy (x 1000, oil immersion) using the classical $\mathrm{H}$-Score method:

$$
\mathrm{S}=1 \times \mathrm{N}_{1}{ }^{+}+2 \times \mathrm{N}_{2}{ }^{+}+3 \times \mathrm{N}_{3}{ }^{+},
$$

where $\mathrm{S}$ is "H-Score" index, $\mathrm{N}_{1}{ }^{+}, \mathrm{N}_{2},{ }^{+}$and $\mathrm{N}_{3}{ }^{+}$are numbers of cells with low, medium or high levels of marker expression.

Low-temperature electron paramagnetic resonance. The level of "free" iron and rate of $\mathrm{NO}$ generation by inducible NO-synthase were estimated by low-temperature electron paramagnetic resonance (EPR). To determine the level of "free" iron, samples were kept during spectra recording at liquid nitrogen temperature $(77 \mathrm{~K})$. For low-temperature EPR the following parameters were used: stripe width was $1525 \mathrm{G}$, frequency $-9.15 \mathrm{GHz}$, microwave power $40 \mathrm{~mW}$, amplitude modulation $-10.0 \mathrm{G}$, frequency modulation $-100 \mathrm{kHz}$. $g$-Factor was calculated using a standard formula:

$$
g=h v / \beta H,
$$

where $h$ is Plank's constant; $v-$ frequency, $\beta$ - Bohr's magneton; $\mathrm{H}-$ external magnetic field in resonance.

The evaluation of speed of NO generating by inducible NO-synthase in BC cells was conducted at room temperature using technology SpinTrap in the temperature of liquid nitrogen $(77 \mathrm{~K})$. The level of NO was determined using a diethyldithiocarbomate spin trap (Sigma, USA) and EPR technology. The generation of NO was registered during $5 \mathrm{~min}$ followed by cessation of NO generation by liquid nitrogen. The levels of $\mathrm{NO}$ were calculated in $\mathrm{nmol} / 2.5 \cdot 10^{5}$ cells.
Genotoxic activity of LF assessment was performed using a standard classical method of alkaline gel electrophoresis of isolated cells (Comet assay) as described in [7]. After drying the samples were stained with acridine orange (Sigma Aldrich, USA; $2 \mathrm{mg} / \mathrm{ml}$ ). Microscopic analysis was performed using a fluorescent microscope MC 300x FS (Micros, Austria). For each analyzed specimens at least 100 "DNAcomets". Digital images were analyzed by the computer program "CometScore" (TriTek Corp., USA).

Measurement of SOD. SOD activity was detected as described earlier [8]. Briefly, cells were homogenized in the glass homogenizer with $2 \mathrm{ml}$ of $0.1 \mathrm{M}$ PBS. After centrifugation at $3000 \mathrm{rpm}$ for $20 \mathrm{~min}$ supernatant was analyzed for SOD activity using radiospectrometer EPR-1307 (ZEPS AN, Russia) at room temperature.

Flow cytometry. Determination of the reactive oxygen species (ROS), cardiolipin and glutathione content, the study of apoptosis and DNA status of cells were conducted using specific dyes for flow cytometry on Beckman Coulter EPICS ${ }^{\circledR}$ XL Flow Cytometer (Beckman Coulter, USA). To study of ROS generation by flow cytometry $\mathrm{CM}-\mathrm{H}_{2}$ DCFDA dye (Thermo Fisher Scientific, USA) was used following the manufacturer's recommendations. Assessment of the content of glutathione in BC cells was performed using dye CellTracker ${ }^{\mathrm{TM}}$ GreenCMFDA dye (Thermo Fisher Scientific, USA), following the manufacturer's recommendations. To visualize the distribution of cardiolipin in mitochondria acridine orange 10-nonyl bromide (NAO; Invitrogen, USA) dye was used as described in [9]. To determine the number of apoptotic cells the staining with Annexin A5-FITC Kit (Beckman Coulter, France) was used as described in [10]. Charts of density distribution of the studied parameters were analyzed using FCS Express V3 (De Novo Software, USA). DNA status was assessed using ModFit v3.2 software (Verity Software House, USA).

Statistical analysis. Experimental data were analyzed using the Student's $t$-test. $p$-values less than 0.05 were considered statistically significant. Statistical analysis of the obtained data was performed using the STATISTICA 6.0 software (Dell, USA).

\section{RESULTS AND DISCUSSION}

$B C$ is a heterogeneous disease that varies by the morphological and molecular features as well as by the clinical course, and therefore requires different approaches to diagnosis and treatment. Knowledge about the role of metalloproteins in malignant transformation and tumor progression as important components of metabolism attaches great importance to date. In this respect in recent years become increasingly relevant studying of disorders of iron metabolism and possibilities of its modification by exogenous agents [11]. LF is very perspective agent for this purpose, because it is normal iron-regulating protein, possessing immune and antitumor activities [12].

We established more pronounced cytotoxic activity of LF on receptor-negative MDA-MB-231 and 
MDA-MB-468 cells compared to receptor-positive MCF-7 and T47D cells. As seen from the data presented in Fig. 1, IC 30 dose for MCF-7 and T47D cells was $10 \mathrm{\mu g} / \mathrm{ml}$, whileforMDA-MB-231 andMDA-MB-468cells the similar dose of exogenous LF caused the death of $45 \%$ and $40 \%$ of cells, respectively. The dose of LF, that causes death in $30 \%$ of the cells with negative receptor status, was $5 \mu \mathrm{g} / \mathrm{ml}$. To study the molecular effects of $L F$ we used $I_{30}$ doses; cells were treated with LF for $24 \mathrm{~h}$.

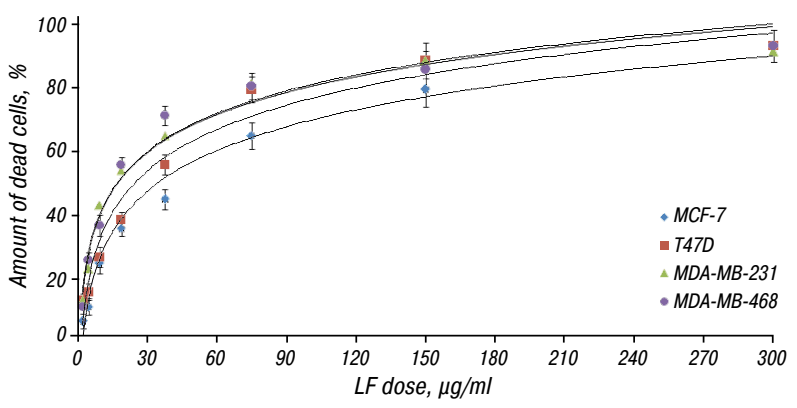

Fig. 1. Cytotoxic activity of exogenous LF on human BC cells with different receptor status

It is known that one of the main functions of LF is the regulation of the concentration of iron ions in the cells. Iron is a key element for the normal processes of proliferation and cell growth. Intracellular iron is carefully maintained and controlled at a certain level by many mechanisms. It is known that cancer cells have a significant increase in iron content due to their enhanced metabolic and proliferative needs [13]. On the other hand, the content of "free" iron in cancer cells may decrease because of its exhaustion, which also indicates an increased need for this element in cells that rapidly grow and divide. However, the excess iron can lead to the formation of dangerous ROS, which creates conditions for the initiation and progression of tumors. Increased number of ROS also can be caused by any other cell response to stress. This is the adaptation to extreme conditions, in which ROS act as second messengers participating in signal transduction and activation of transcription factors of certain genes, including those encoding enzymes and antioxidants.

The physiological level and rate of generation of ROS in the cells are maintained at a constant level due to the existence of multi-antioxidant protection system. Higher concentrations of ROS due to shifting the balance between the processes of their formation and detoxification are a precondition for infringement of functional activity of cells and pathological processes [14]. Therefore, the next series of experiments were aimed at studying changes on the level of "free" iron in LF-treated BC cells with different hormone receptor status.

We found a significant increase of "free" iron content after treatment of BC cells with LF (Fig. 2). Thus, in the treated receptor-positive MCF-7 and T47D cells, the levels of "free" iron increased to 1.7-1.9-fold and were $0.98 \pm 0.11 \cdot 10^{16} \mathrm{spin} / \mathrm{ml}$ and $0.88 \pm 0.1 \cdot 10^{16} \mathrm{spin} / \mathrm{ml}$.
Treatment of MDA-MB-231 and MDA-MB-468 cells under similar conditions led to increased levels of "free" iron in 2.3-2.5-fold (see Fig. 2).

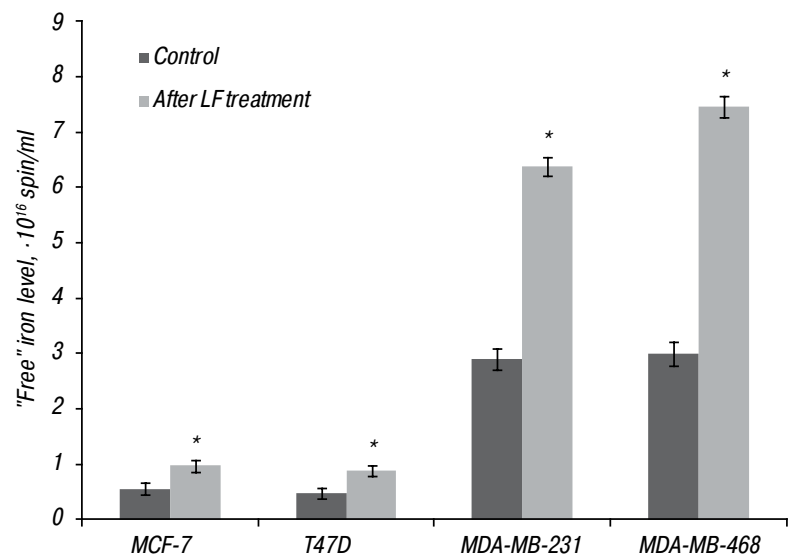

Fig. 2. The levels of "free" iron in BC cells with different receptor status under the influence of exogenous LF. ${ }^{*} p<0.05$ compared to untreated cells

Culvation of BC cells with exogenous LF also led to an increase in ROS generation (Fig. 3). Thus, in treated MCF-7 and T47D cells intracellular levels of ROS increased by 2 times and amounted up to $3.32 \pm 0.24$ r. u. and $5.21 \pm 0.67$ r. u. , respectively. Treatment of MDA-MB-231 and MDA-MB-468 cells with $L F$ also led to an increase in intracellular levels of ROS at 1.76- and 1.63-fold, respectively.

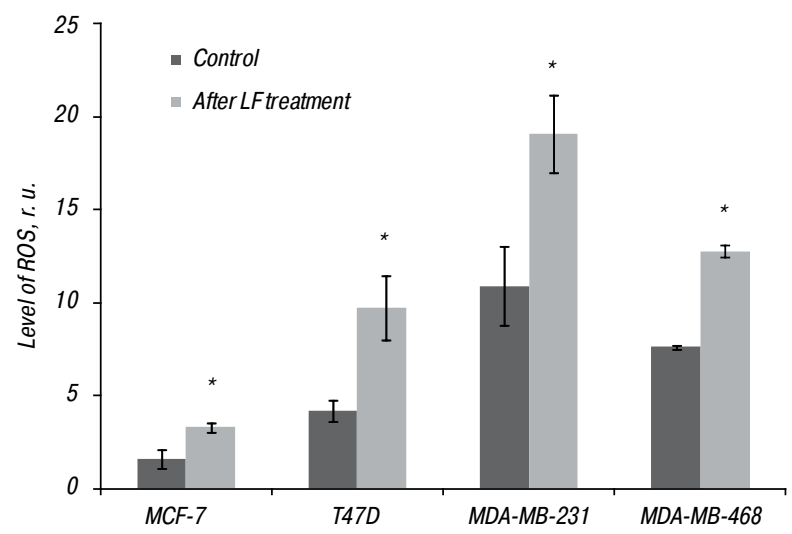

Fig. 3. The levels of ROS in BC cells with different receptor status under influence of exogenous LF. ${ }^{*} p<0.05$ compared to untreated cells

During the study of NO generation speed by inducible NO-synthase in BC cells after cultivation with $L F$, we established an increase of this indicator in all studied cell lines. As can be seen from the data presented in Fig. 4, in the hormone-responsible MCF-7 and T47D cells the rate of NO-generation by exogenous LF increased in 1.5-1.6-fold and amounted up to $271.75 \pm 10.45 \mathrm{nmol} / 2.5 \cdot 10^{5}$ and $256.70 \pm 11.81 \mathrm{nmol} / 2,5 \cdot 10^{5}$, respectively. In receptor-negative MDA-MB-231 and MDA-MB-468 cells NO generation rate raised of more than $90 \%$.

Thus, LF treatment of receptor-positive and receptor-negative BC cells resulted in oxidative stress. This is evidenced by the increase of "free" iron, intracellular levels of ROS, and NO generation speed by inducible 


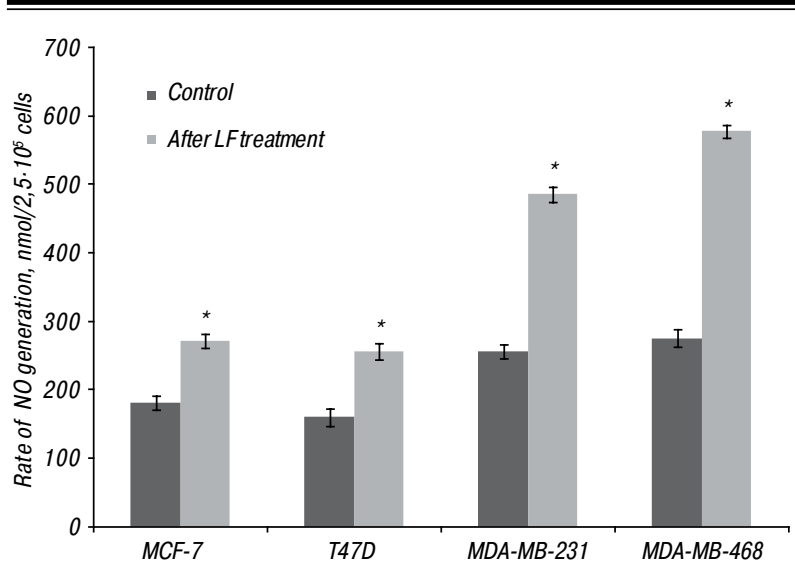

Fig. 4. The rate of $\mathrm{NO}$ generation by inducible NO-synthase in human $B C$ cells with different receptor status under influence of exogenous LF. ${ }^{\star} p<0.05$ compared to untreated cells

NO-synthase after LF treatment. The most serious violations of oxidative balance rates after LF effect we observed in receptor-negative $\mathrm{BC}$ cells.

There is evidence about LF ability to disrupt the mitochondrial membrane, which is associated with increased levels of ROS and release of cytochrome C [15]. ROS oxidize polyunsaturated acyl chains of cardiolipin, which is a signal for triggering apoptosis [16]. As mentioned above, the system of glutathione is one of the most powerful intracellular antioxidative mechanisms. The thiol groups of glutathione in the reduced state are in a high concentration in cells, which allows recovering disulfide bonds. The balance between restored and oxidized forms of glutathione is an important parameter that determines the level of oxidative stress in cells [17].

Another powerful antioxidant enzyme is oxidereducing SOD that catalyzes the dismutation of $\mathrm{O}^{2-}$ radicals and prevents the transformation of superoxide anion radicals into the hydroxyl radical. Also, SOD is an acceptor of free oxygen radicals, thereby preventing lipid and protein peroxidation. Normally the SOD supports basic concentration of superoxide radicals at a certain level, thereby protecting cells from damaging effect of $\mathrm{O}^{2-}$ and hydroxyl radicals that can be generated from $\mathrm{O}^{2-}$ and $\mathrm{HO}$ [18].

In our study, we tested the reduced form of glutathione using dye CellTrackerGreen (CMFDA), which interacts with $\mathrm{SH}$-groups of glutathione, by flow cytometry. On Fig. 5 are represented typical histo-
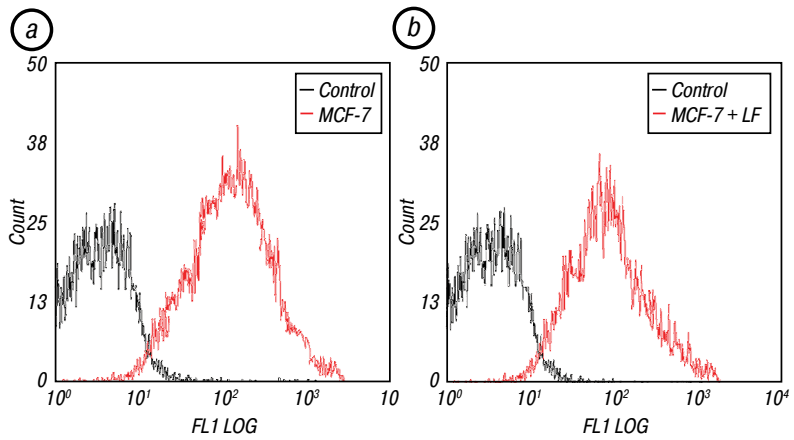

Fig. 5. Typical flow cytometry histograms of glutathione content in BC cells: $a-$ untreated cells; $b-\mathrm{LF}$-treated cells grams of reduced glutathione in the $\mathrm{BC}$ cells. As can be seen from the data presented in Fig. 6, LF treatment in a dose corresponding to $\mathrm{IC}_{30}$, for $24 \mathrm{~h}$ resulted in a decrease in intracellular glutathione content in studied BC cell lines, indicating a transition of glutathione in the oxidized state. The most significant decrease (in 4.3- and 2.3-fold) glutathione content was observed in MCF-7 and MDA-MB-468 cells. In the T47D and MDA-MB-231 cells the glutathione level decreased by 1.9- and 1.4-fold, respectively, and amounted to $3.57 \pm 0.82 \mathrm{r}$. u. and $3.32 \pm 0.45 \mathrm{r}$. u., respectively. Established differences in levels of glutathione in MCF-7 and MDA-MB-468 cells are likely caused by the high proliferative activity of these cells.

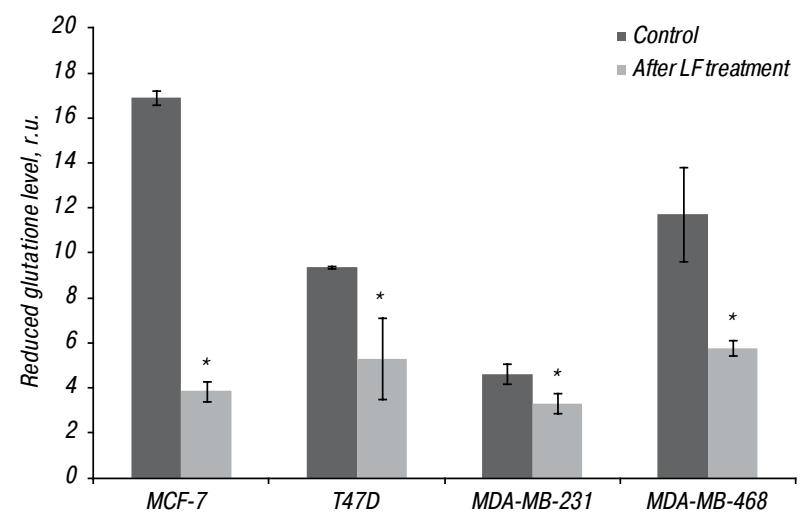

Fig. 6. The reduced glutathione levels in $B C$ cells with different receptor status under influence of exogenous LF. ${ }^{*} p<0.05 \mathrm{com}$ pared to untreated cells

LF treatment also led to reduced activity of SOD in 1.2-1.7-fold compared to baseline in all studied cell lines (Fig. 7).

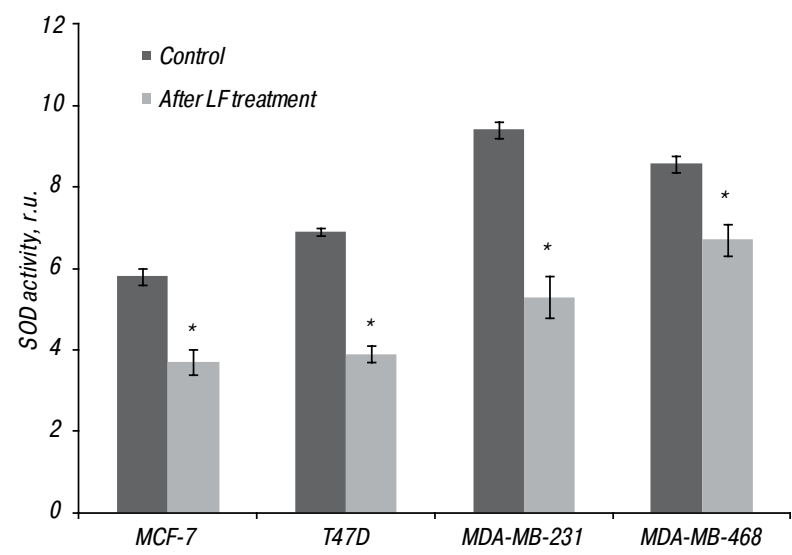

Fig. 7. SOD activity in $B C$ cells with different receptor status under influence of exogenous LF. ${ }^{\star} p<0.05$ compared to untreated cells

According to the literature, one of the mechanisms of exogenous LF action is initiating apoptosis in malignant cells [19]. Thus, Fujita et al. found that treatment of colorectal cancer cells with LF increases the expression of death receptor CD95 and proapoptotic Bax and Bid proteins [19]. We established that exposure to exogenous LF of studied BC cells caused cell death mainly by apoptosis. As it is shown in Table 1 , under the influence of LF $25.5 \%$ and $22.6 \%$ of the MCF-7 and 
T47D cells, respectively, were in a state of apoptosis. The highest percentage of apoptotic cells under exogenous $L F$ treatment was observed in receptor-negative MDA-MB-468 and MDA-MB-231 cells (43.2 and 41.3\%, respectively). Therefore, LF treatment resulted in an increase of apoptotic cells in receptor-positive $\mathrm{BC}$ cells (by $14 \%$ in MCF-7 and $17 \%$ in T47D cells) as well as in receptor-negative BC cells (by $33 \%$ in MDA-MB-231 cells and $29 \%$ in MDA-MB-468 cells).

Table 1. Percentage of apoptotic cells in BC cell lines before and after LF treatment

\begin{tabular}{|c|c|c|}
\hline \multirow{2}{*}{ Cell line } & \multicolumn{2}{|c|}{ Apoptotic cells, $\%$} \\
\hline & Control & After LF treatment \\
\hline MCF-7 & $8.1 \pm 3.1$ & $25.5 \pm 2.8^{*}$ \\
\hline T47D & $8.7 \pm 2.9$ & $22.6 \pm 3.2^{*}$ \\
\hline MDA-MB-231 & $10.6 \pm 3.7$ & $43.2 \pm 2.7^{\star}$ \\
\hline MDA-MB-468 & $12.2 \pm 4.0$ & $41.3 \pm 3.8^{*}$ \\
\hline
\end{tabular}

Note: ${ }^{\star} p<0.05$ compared to untreated cells.

Since it is known that a key role in the initiation of apoptosis belongs to cardiolipin - an essential phospholipid component of the mitochondria membranes - on the next step we studied the changes in its content in the BC cells under the influence of exogenous LF. As can be seen from the data presented in Fig. 8, $24 \mathrm{~h} \mathrm{LF}$ expose resulted in a decrease in NAO fluorescence intensity in all investigated cells lines. So, upon LF treatment the levels of non-oxidized cardiolipin in MCF-7 and T47D cells decreased by 1.6and 1.7-fold, respectively. In MDA-MB-231 cells cardiolipin levels decreased 2.4-fold and amounted to $57.29 \pm 7.65 \mathrm{r}$. u., whereas in MDA-MB-468 cell line cardiolipin levels decreased by 2.1 -fold and amounted to $136.07 \pm 74.20 \mathrm{r}$. u., indicating the development of oxidative stress. Unidirectional reducing of NAO fluorescence in the cells of all studied lines under the LF impact demonstrates the ability of LF to oxidize mitochondrial cardiolipin. The most significant changes in cardiolipin content we observed in receptor-negative MDA-MB-231 and MDA-MB-468 cells.

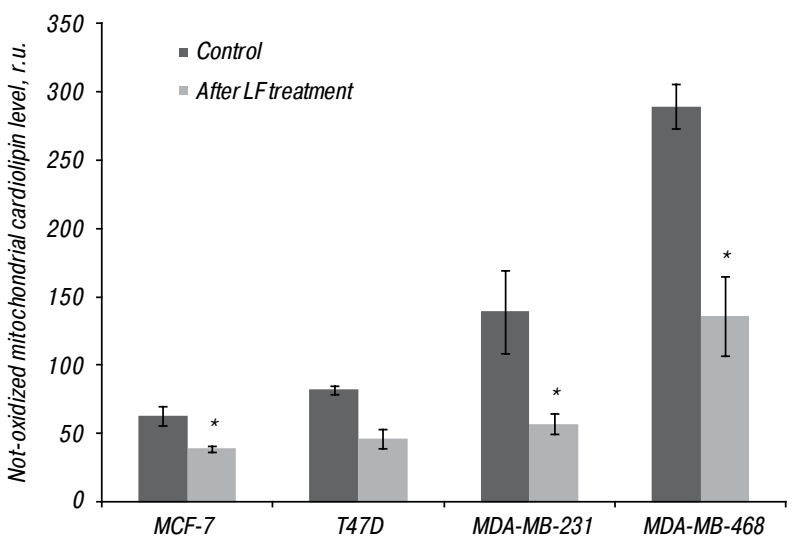

Fig. 8. The levels of not-oxidized mitochondrial cardiolipin in $\mathrm{BC}$ cells with different receptor status under the influence of exogenous LF. ${ }^{\star} p<0.05$ compared to untreated cells

We determined that the LF is able to initiate the apoptotic program in a more severe form in receptornegative cells not only due to the oxidation of cardiolipin, but also by influencing the level of expression of proand antiapoptotic proteins. Thus, in the LF-treated
MCF-7 and T47D cells expression level of proapoptotic Bax protein increased by $10-13 \%$ to $223.4 \pm 2.6$ and $187.3 \pm 4.8 \mathrm{H}$-score points, respectively, while in the MDA-MB-231 and MDA-MB-468 cells expression level of Bax after LF treatment increased by $16-17 \%$ and amounted to $180.7 \pm 3.8$ and $167.4 \pm 4.7 \mathrm{H}$-score points, respectively (Table 2). The study of the expression of antiapoptotic $\mathrm{Bcl}-2$ protein after exogenous LF influence showed a decrease of Bcl-2 in cells of all studied lines (see Table 2). Thus, Bcl-2 expression in receptorpositive BC cells after LF treatment decreased by 16$18 \%$, while the level of Bcl-2 in the MDA-MB-231 and MDA-MB-468 cells decreased at $21-23 \%$.

Table 2. The levels of pro- and anti-apoptotic proteins in BC cells with different receptor status

\begin{tabular}{lcccc}
\hline & \multicolumn{4}{c}{ Protein level, H-score } \\
\cline { 2 - 5 } Cell line & Proapoptotic Bax protein & Antiapoptotic Bcl-2 protein \\
\cline { 2 - 5 } & Control & $\begin{array}{c}\text { After } \\
\text { LF treatment }\end{array}$ & Control & $\begin{array}{c}\text { After LF } \\
\text { treatment }\end{array}$ \\
\cline { 2 - 5 } & $195.1 \pm 4.5$ & $223.0 \pm 2.6^{*}$ & $298.1 \pm 2.1$ & $252.0 \pm 0.8^{*}$ \\
MCF-7 & $165.0 \pm 3.7$ & $187.3 \pm 4.8^{*}$ & $286.1 \pm 5.8$ & $240.2 \pm 6.1^{*}$ \\
T47D & $156.2 \pm 2.8$ & $180.0 \pm 3.8^{\star}$ & $258.0 \pm 2.7$ & $208.1 \pm 3.6^{*}$ \\
MDA-MB-231 & $167.2 \pm 4.7^{*}$ & $247.2 \pm 3.1$ & $190.4 \pm 4.8^{*}$ \\
MDA-MB-468 & $142.1 \pm 4.6$ & $167.2 \pm$
\end{tabular}

Note: ${ }^{\star} p<0.05$ compared to untreated cells.

It is known that an important LF feature is its ability to bind to nucleic acids and thus affect the proliferative activity of cells. Also, LF is able to stop cell growth by modulating the expression and activity of $\mathrm{G}_{1}$ cyclin-dependent kinases and activation of transcription [20, 21]. There are also reports of a possible genotoxic effect of LF. Given the above, the next step we investigated the changes of cell cycle in LF-treated BC cells. As seen from the data presented in Table 3, cytotoxic effects of $L F$ followed by blocking cell cycle at $G_{2} / M$ phase, particularly in receptor-negative cells and 1.4-2.5-fold decrease in cell number in the synthetic phase of the cell cycle of all studied BC cell lines. At the same time, we have confirmed the LF genotoxic action using the Comet assay. We identified a significant increase $(p<0.05)$ the percentage of DNA in the comet tail in 1.9- and 2.3-fold, respectively, under the influence of LF in MDA-MB-468 and MDA-MB-231 cells with negative receptor status (Table 4).

Table 3. Cell cycle distribution of receptor-positive and receptor-negative $\mathrm{BC}$ cells

\begin{tabular}{lcccccc}
\hline \multirow{2}{*}{ Cell line } & \multicolumn{3}{c}{ Control, \% } & \multicolumn{4}{c}{ After LF treatment, \% } \\
\cline { 2 - 7 } & $\mathrm{G}_{1}$ & $\mathrm{G}_{2}+\mathrm{M}$ & $\mathrm{S}$ & $\mathrm{G}_{1}$ & $\mathrm{G}_{2}+\mathrm{M}$ & $\mathrm{S}$ \\
\hline MCF-7 & $51.4 \pm$ & $11.8 \pm$ & $36.8 \pm$ & $72.6 \pm$ & $9.1 \pm$ & $18.3 \pm$ \\
& 2.8 & 1.3 & 3.6 & $3.1^{\star}$ & 2.0 & $1.6^{\star}$ \\
T47D & $55.3 \pm$ & $19.8 \pm$ & $24.9 \pm$ & $71.2 \pm$ & $11.4 \pm$ & $17.4 \pm$ \\
& 4.1 & 3.4 & 2.6 & $2.9^{\star}$ & $1.9^{\star}$ & $2.1^{\star}$ \\
MDA-MB-231 & $51.2 \pm$ & $27.5 \pm$ & $21.3 \pm$ & $76.6 \pm$ & $13.9 \pm$ & $9.5 \pm$ \\
& 4.8 & 4.2 & 1.8 & 4.2 & $0.4^{\star}$ & $2.7^{\star}$ \\
MDA-MB-468 & $56.7 \pm$ & $22.6 \pm$ & $20.7 \pm$ & $74.8 \pm$ & $17.3 \pm$ & $8.07 \pm$ \\
& 3.9 & 1.9 & 2.1 & $4.0^{\star}$ & $0.7^{\star}$ & $1.9^{\star}$ \\
\hline
\end{tabular}

Note: ${ }^{*} p<0.05$ compared to untreated cells.

Table 4. Percentage of DNA in the comet tail of $B C$ cells with different receptor status

\begin{tabular}{lcc}
\hline \multirow{2}{*}{ Cell line } & \multicolumn{2}{c}{ Tail DNA, \% } \\
\cline { 2 - 3 } & Control & After LF treatment \\
\hline MCF-7 & $5.33 \pm 1.41$ & $9.80 \pm 2.50$ \\
T47D & $5.20 \pm 1.10$ & $9.70 \pm 1.90$ \\
MDA-MB-231 & $6.10 \pm 1.52$ & $14.03 \pm 2.11^{\star}$ \\
MDA-MB-468 & $5.80 \pm 0.90$ & $11.02 \pm 1.90^{\star}$ \\
\hline
\end{tabular}

Note: ${ }^{\star} p<0.05$ compared to untreated cells. 


\section{CONCLUSION}

Exogenous LF causes the increase of ROS levels, speed of NO generation by inducible NO-synthase and the levels of "free" iron in BC cells. Moreover LF effects are more pronounced in receptor-negative MDA-MB-231 and MDA-MB-468 cells. Also, LF treatment causes the decrease in the content of reduced glutathione. We also established the ability of LF to increase the percentage of apoptotic cells and to reduce cardiolipin levels in mitochondria. This, in turn, leads to increased expression of proapoptotic Bax protein and reduction of the expression antiapoptotic Bcl-2 protein. Cytotoxic effects of LF followed by blocking cell cycle at $G_{2} / M$ phase, particularly in receptor-negative cells this process was accompanied by a decrease the number of cells in the synthetic phase of the cell cycle.

So, we can conclude that LF can be used as an exogenous modifier of such cancer features as oxidant/ antioxidant balance, apoptotic rates, and cell cycle progression. Our results demonstrated that LF could be considered as a promising agent, which can be used in low doses and the obtained data create the basis for further in vivo investigations.

\section{REFERENCES}

1. Beguin Y, Aapro M, Ludwig H, et al. Epidemiological and nonclinical studies investigating effects of iron in carcinogenesis - a critical review. Crit Rev Oncol Hematol 2014; 89: $1-15$.

2. Xue X, Shah YM. Intestinal iron homeostasis and colon tumorigenesis. Nutrients 2013; 5: 2333-51.

3. Bystrom LM, Rivella S. Cancer cells with irons in the fire. Free Radic Biol Med 2015; 79: 337-42.

4. Jian J, Yang Q, Dai J, et al. Effects of iron deficiency and iron overload on angiogenesis and oxidative stress a potential dual role for iron in breast cancer. Free Radic Biol Med 2011; 50: 841-7.

5. Pearl CA, Roser JF. Lactoferrin expression and secretion in the stallion epididymis. Reprod Biol 2014; 14: 148-54.

6. Chekhun VF, Borikun TV, Lukianova NY. Effect of 5-azacytidine on miRNA expression in human breast cancer cells with different sensitivity to cytostatics. Exp Oncol 2016; 38: $26-30$.

7. Dhawan A, Anderson D, de Pascual-Teresa S, et al. Evaluation of the antigenotoxic potential of monomeric and dimeric flavanols, and black tea polyphenolics against hetero- cyclic amine-induced DNA damage in human lymphocytes using the Comet assay. Mutat Res 2002; 515: 39-56.

8. Ogura R, Ueta H, Sugiyama M, Hidaka T. Distribution of superoxide dismutase activity in the epidermis: measurement with electron spin resonance spin trapping. J Invest Dermatol 1990; 94: 227-9.

9. Leung CW, Hong Y, Hanske J, et al. Superior fluorescent probe for detection of cardiolipin. Anal Chem 2014; 86: $1263-8$.

10. Chen S, Cheng AC, Wang MS, Peng X. Detection of apoptosis induced by new type gosling viral enteritis virus in vitro through fluorescein annexin V-FITC/PI double labeling. World J Gastroenterol 2008; 14: 2174-8.

11. Chifman J, Laubenbacher R, Torti SV. A systems biology approach to iron metabolism. Adv Exp Med Biol 2014; 844: $201-25$

12. Zimecki M, Kruzel ML. Milk-derived proteins and peptides of potential therapeutic and nutritive value. J Exp Ther Oncol 2007; 6: 89-106.

13. Lui GY, Kovacevic Z, Richardson V, et al. Targeting cancer by binding iron: Dissecting cellular signaling pathways. Oncotarget 2015; 6: 18748-79.

14. Liemburg-Apers DC, Willems PH, Koopman WJ, Grefte $\mathrm{S}$. Interactions between mitochondrial reactive oxygen species and cellular glucose metabolism. Arch Toxicol 2015; 89: 1209-26.

15. Acosta-Zaldívar M, Andrés MT, Rego A, et al. Human lactoferrin triggers a mitochondrial- and caspase-dependent regulated cell death in Saccharomyces cerevisiae. Apoptosis 2016; 21: 163-73.

16. Maguire JJ, Tyurina YY, Mohammadyani D, et al. Known unknowns of cardiolipin signaling: The best is yet to come. Biochim Biophys Acta 2017; 1862: 8-24.

17. Giustarini D, Galvagni F, Tesei A, et al. Glutathione, glutathione disulfide, and S-glutathionylated proteins in cell cultures. Free Radic Biol Med 2015; 89: 972-81.

18. McCord JM. Human disease, free radicals, and the oxidant/antioxidant balance. Clin Biochem 1993; 26: 351-7.

19. Fujita $K$, Matsuda $E$, Sekine $K$, et al. Lactoferrin modifies apoptosis-related gene expression in the colon of the azoxymethane-treated rat. Cancer Lett 2004; 213: 21-9.

20. Damiens E, El Yazidi I, Mazurier J, et al. Lactoferrin inhibits $\mathrm{G} 1$ cyclin-dependent kinases during growth arrest of human breast carcinoma cells. J Cell Biochem 1999; 74: 486-98.

21. Xiao Y, Monitto CL, Minhas KM, Sidransky D. Lactoferrin down-regulates $\mathrm{G} 1$ cyclin-dependent kinases during growth arrest of head and neck cancer cells. Clin Cancer Res 2004; 10: 8683-6. 